\title{
Diacronie
}

Studi di Storia Contemporanea

$N^{\circ} 9,1 \mid 2012$

Quando la classe operaia andava in paradiso

\section{Abdón Mateos, Historia de la UGT. Vol. V: Contra la dictadura franquista, 1939-1975}

\section{Esteban Elena González}

\section{Q OpenEdition}

Edición electrónica

URL: http://journals.openedition.org/diacronie/3111

DOI: 10.4000/diacronie.3111

ISSN: 2038-0925

Editor

Association culturelle Diacronie

Referencia electrónica

Esteban Elena González, «Abdón Mateos, Historia de la UGT. Vol. V: Contra la dictadura franquista, 1939-1975 », Diacronie [En línea], N 9, 1 | 2012, documento 19, Puesto en línea el 29 enero 2012, consultado el 23 septiembre 2020. URL : http://journals.openedition.org/diacronie/3111 ; DOI : https://doi.org/10.4000/diacronie.3111 


\section{Diacronie}

N. 9 | 1|2012 Quando la classe operaia andava in paradiso

19/

\section{RESEÑA:}

\section{Abdón, MATEOS, Historia de la UGT V. Contra la dictadura franquista, 1939-1975, Madrid, 2008, Siglo XXI, 273 pp.}

por Esteban ELENA GONZÁLEZ *

\section{Luigi Longo: da traghettatore a protagonista ${ }^{1}$}

¿Cómo transcurrieron los trente glorieuses para un sindicato que vivió a caballo entre el exilio y el anhelo por conseguir un régimen democrático en España? ¿Fue la UGT un producto netamente europeo en este periodo, impregnado del ideario de las grandes alianzas sindicales internacionales que le prestaron auxilio en los años de la dictadura franquista? ¿Cómo se produjo su refundación desde los rescoldos militantes de la posguerra hasta su renacimiento en la transición española? A estas y otras preguntas trata de dar respuesta el quinto volumen de la colección de historia de la UGT editada por Siglo XXI, titulado Contra la dictadura franquista, 1939-1975, de Abdón Mateos.

El autor es uno de los mayores especialistas consolidados en la historia del socialismo español en el periodo comprendido entre la Guerra Civil y el final del franquismo. Ha contribuido al fomento de los estudios sobre la historia reciente de España desde la dirección del Centro de Investigaciones de la Democracia Española, la revista Historia del Presente, la Asociación de Historiadores del Presente o la cátedra del exilio de la Universidad Nacional de Educación a Distancia (UNED). Esta concreción temática en sus líneas de investigación es un fiel reflejo de sus trabajos publicados, entre los que destacan El PSOE contra Franco (Madrid, P. Iglesias 1993), Las izquierdas españolas desde la guerra civil hasta 1982 (Madrid, UNED, 1997), el más reciente Historia del antifranquismo. Historia, interpretación y uso público

\footnotetext{
${ }^{1}$ Una prima versione di questa recensione è apparsa nel numero 5 del $2011 \mathrm{di}$ «Marx ventuno».
} 
(Barcelona, Flor del Viento, 2011) o Exilio y Clandestinidad: La Reconstrucción de UGT (1939-1977) (Madrid, UNED, 2002) siendo la presente una revisión de esta última obra. El libro se estructura en cuatro capítulos, correspondientes a la organización del sindicato, la represión ejercida por el régimen franquista, las relaciones internacionales de la UGT y finalmente la lucha sindical contra la dictadura en España.

No cabe duda de que la situación de la UGT tras la Guerra Civil era muy precaria. Con una militancia diezmada, fragmentada y varias cabezas organizativas visibles tanto en Francia como en México, los dirigentes ugetistas comenzaron una particular travesía en el desierto consolidando el sindicato en el país vecino (1944) donde consiguieron la legalidad en 1949, a la vez que lo reorientaron ideológicamente entre los años cuarenta y cincuenta. En "La Refundación de la UGT" (cap.1) el sindicato, unido estrechamente

al PSOE en el exilio, pone fin al espíritu frentepopulista de preguerra tratando de volver a los principios fundacionales inspirados por Pablo Iglesias. De esta forma se atisba un creciente recelo hacia el partido comunista, fruto de la experiencia caballerista de la Guerra Civil. La Unión General de Trabajadores comenzó a moderarse, definiéndose europeísta, escasamente atlantista, militarmente neutralista, anticomunista y crítica con el marxismo, a pesar ser éste un término mantenido para definirse a sí misma.

En esta etapa temprana en el exilio la primera clandestinidad en España tuvo muy poco peso. El estado franquista de los primeros decenios buscó la exclusión de los derrotados, conduciendo a sucesivas desarticulaciones de las ejecutivas socialistas y ugetistas del interior en los años cuarenta y cincuenta. Hasta bien entrados los cincuenta la clandestinidad no fue ganando relevancia, creándose federaciones en el interior en 1957 e iniciándose poco después la dirección compartida con Francia (1958) y los comités industriales en el interior durante los años sesenta. Fue en esta década además cuando UGT comenzó a diferenciarse del PSOE como marca propia, consolidándose a principios de 1971 una renovación de la ejecutiva protagonizada por los jóvenes fruto de la segunda generación del exilio. Este rejuvenecimiento, que las JSU venían reclamando desde los años sesenta, supuso un distanciamiento respecto a la experiencia de la Guerra Civil.

Como sindicato histórico, la UGT fue junto a la CNT entre los grupos que más sufrieron la represión durante el franquismo, aunque desde la década de los sesenta la primera vivió una situación de semitolerancia. "La destrucción del sindicalismo" (cap. 2) da buena cuenta de la suerte de los más de 80.000 afiliados que tuvo la UGT durante la Guerra Civil. De ellos, la mitad fueron represaliados, y de estos 20.000 se implicaron en organizaciones sindicales en el exilio. La otra mitad no represaliada desapareció por 
muerte natural, falta de movilización o desarraigo político, produciéndose una ruptura de la continuidad orgánica en muchas regiones españolas. El propio autor constata cómo la UGT en el exilio era conocida por los españoles, pero no resultaba así con la clandestina dentro de España.

La disyuntiva para los clandestinos represaliados fue unívoca entre 1945 y 1950: la huida a Francia, que se mantuvo hasta principios de los años sesenta. Sin embargo, la indulgencia temprana de las autoridades francesas de la posguerra mundial fue seguida a partir de 1948 por una postura más dura acentuada por las políticas del general De Gaulle. Desde 1956 además, la dirección en el exilio trató de disuadir la incorporación de nuevos refugiados en suelo francés, ya que su estrategia en España pasaba por aprovechar la experiencia de los miembros que se encontraban en el interior para la lucha en la península. La última caída de la dirección clandestina se produjo en 1958, marcando un punto de inflexión en el trato dado al sindicato por parte del régimen franquista. El Plan de Estabilización y la implícita dependencia económica de Occidente, el ingreso paulatino de España en diversas organizaciones internacionales y la solidaridad europea existente con los movimientos opositores a la dictadura, hicieron que Franco no pudiera volver a la represión de posguerra. El trato a los partidos y sindicatos a la derecha de la UGT entró en fase de ambigüedad, alternando periodos cuasi indulgentes con otros de fuerte represión a lo largo de los sesenta.

La UGT construyó un entramado de relaciones internacionales para su estrategia de acoso al régimen franquista. En el tercer capítulo, "Las Relaciones Internacionales de la UGT", se explica cómo ya desde 1945-50 las secciones en el exilio de la lucharon por su reconocimiento internacional, especialmente a través de su vinculación a la Confederación Internacional de Organizaciones Sindicales Libres (CIOSL) fundada en 1949. No obstante, hasta los años sesenta la CIOSL no consideró prioritaria la cuestión española, cuando fue pergeñada una nueva táctica a largo plazo: gradualista, de apoyo al Plan de Estabilización, al ingreso de España en varios organismos internacionales y fomento de la unidad de acción sindical. Este nuevo planteamiento agravó las diferencias entre la UGT y la central internacional, desencadenando un periodo de desconfianza mutua. La UGT rechazó cualquier balón de oxígeno en forma de apoyo económico o reconocimiento internacional al régimen de Franco, creyendo que no serviría para estrangularlo, sino para todo lo contrario. Esta nueva postura llevó a la UGT al inicio de acciones unilaterales para defender sus planteamientos, saldadas con rotundos fracasos. Afortunadamente para la organización a finales de los sesenta CIOSL concluyó que España se encontraba en un momento de coyuntura crítica de cara a un posible final del régimen, y subrayó la necesidad de promover la unidad de acción 
de todos los sindicatos españoles, contando en primer lugar con los de viejo cuño, como la UGT, lo que supuso la reconciliación entre ambos. Una de las medidas más destacadas por parte de la CIOSL fue el incremento de los recursos del sindicato español a través de la solidaridad internacional para afianzar su papel central y ante todo, mermar el predominio comunista con el que amenazaba por entonces CCOO. De dos millones de pesetas recibidos por la CIOSL en 1974, la UGT pasó a recibir entre cuarenta y sesenta en 1977, el triple que la ayuda recibida por Comisiones Obreras. Estas medidas muestran la recuperación de confianza de la CIOSL en la UGT, manifestada en la buena acogida de la renovación parcial de la cúpula ugetista en 1971. Hay que tener en cuenta todo lo que ello supuso respecto a la incorporación de una generación que no había participado en la Guerra Civil. Finalmente, este respaldo fue notoriamente visible con la asistencia de personalidades del sindicalismo internacional de primera fila al XXX Congreso de la UGT.

Queda por esbozar cómo se desarrolló la lucha contra el régimen. "La Lucha Sindical contra la Dictadura" (cap.4) relata el desarrollo de un sindicalismo político por parte de la UGT en el exilio, que desde 1947 ofreció la formación de una plataforma política republicana con la condición de excluir a los comunistas. La obra analiza pormenorizadamente el caso de la CNT, cuyas relaciones fluctuaron del enfrentamiento a la alianza. A pesar de su división interna, la CNT fue un buen socio para colaborar motivados, como la UGT, por sus deseos de supervivencia y para contrarrestar la influencia comunista. La convergencia de los proyectos tuvo dos puntos débiles: el interés de UGT a partir de 1959 por abrirse a otros sindicatos, y la extensión de la alianza UGT-CNT a España, donde los dos sindicatos históricos se mostraban débiles frente a los de nuevo cuño. En este entorno de dificultades, merece especial mención la aparición de nuevas alianzas sindicales que supusieron una fuerte competencia para UGT en los sesenta, en especial ASOC (Alianza Sindical Obrera de Cataluña) posteriormente a nivel nacional ASO. Estas escisiones del interior, que reclamaban la autonomía frente a la UGT del exilio, propugnaron un nuevo sindicalismo de calle, con nuevos instrumentos alejados de la mera memoria histórica de la UGT. De igual forma, a partir de 1964 existieron contactos con USO, Unidad Sindical Obrera, cristiana y autogestionaria, iniciándose la unidad de acción cuatro años más tarde, no sin discrepancias, ya que esta prefería un sindicalismo ajeno a los partidos políticos. El principal mecanismo de acción de la UGT fue la huelga. Su planteamiento de lucha pasaba por un paro general que trajera el colapso del régimen, disgregando a las fuerzas que lo sostenían. La primera general fue la del País Vasco en 1947, quizás la última expresión de resistencia tras la Guerra Civil, en palabras de José María 
Garmendia y Lorenzo Espinosa. Los ciclos conflictivos fueron varios: 1945-1947; 19561958 y a partir de 1962 uno nuevo ligado al cambio de coyuntura económica, en el que ya se produjo una gran solidaridad europea con los represaliados, siendo 1970 el año a partir del que UGT acordó estar presente en todas las huelgas declaradas en el país. Una de las principales contribuciones de la obra es la puesta al día sobre cómo se produjo la reestructuración de la UGT, particularmente en los años anteriores a la muerte de Franco. La tesis de Mateos rebate la anteriormente defendida por Santos Juliá en Los Socialistas en la política española (1879-1982) que abogaba por una ruptura en 1974 entre la generación del exilio y el interior. Mateos apuesta por realzar la importancia de la generación de los niños de la guerra. Es decir, la segunda generación del exilio, aquellos que dejaron España nada más comenzar el conflicto, serían los impulsores de la renovación de la UGT. Se produciría de esta forma continuidad en lugar de la ruptura. Esta regeneración estuvo apoyada, además por los congresos de 1971 y 1976, sustentada por el distanciamiento y la autonomía conseguidos respecto al PSOE ya en los setenta.

La segunda aportación fundamental es el estudio de las relaciones exteriores de la UGT. Sin el vital apoyo económico, asistencia teórica y asesoramiento, influjo ideológico procedente de las centrales sindicales europeas e internacionales, no podría entenderse la evolución de la UGT en esta etapa. Este influjo a veces se produjo por simple ósmosis y otras por imposición de criterios por parte de las centrales sindicales internacionales. Especialmente decisivo resultó para la moderación de la UGT a la hora forzar al sindicato a integrar a las asociaciones de nuevo cuño surgidas en España. En todo caso, la relación fue bidireccional. UGT recuperó de forma temprana el valor de la democracia como un fin en sí mismo y se alejó de la revolución fruto de su experiencia traumática en la Guerra Civil y a través del influjo europeo, mientras que el sindicato trató de orientar a los trabajadores españoles emigrados a Europa, asesorando a las centrales sindicales de los países de destino o abriendo oficinas al respecto.

Un tercer aspecto que no está tan desarrollado en la obra es la explicación de la competencia existente entre centrales sindicales en España (entre CNT y UGT, y las de nuevo cuño como CCOO, u otras como JOC y HOAC) De igual modo una sugerencia para posteriores revisiones sería la de incluir las razones por las que UGT se aproximó en mayor medida a un sindicato teóricamente más radical como CNT y no tanto a Comisiones Obreras. Es cierto que en la obra queda bien planteado el desfase que supuso respecto a la estrategia de UGT la aparición de los nuevos sindicatos y sus nuevos métodos de lucha en la calle, en contraste con la apelación a la memoria que practicaba UGT, pero es un punto en el que caben nuevas inferencias. En el campo 
formal, el hecho de que se trate de una obra de divulgación ha constreñido al autor a una fuerte reducción del aparato crítico. A la estructura cuadripartita del libro, clara y sencilla en su lectura, les siguen unos apéndices con biografías de personajes vinculados al sindicato, fuentes, bibliografía, cronología e ilustraciones, muy útiles para entender la numerosa cantidad de personalidades y organizaciones nombradas en la obra.

En definitiva, el libro constituye uno de los principales referentes para el estudio de la UGT durante el franquismo. Es digna de realzar la dificultad que entraña el empleo de un análisis desde el interior de España y a la par exterior, al tiempo que trazar las líneas de unión entre ellos. De igual modo, constituye un mérito destacado el análisis de la memoria histórica que la UGT tenía sobre sí misma. Sin lugar a dudas, es una obra que enriquece notablemente el acervo disponible hasta este momento sobre la historia reciente de uno de los principales sindicatos españoles. 


\section{* El autor}

Esteban Elena González es Licenciado en Historia por la Universidad de Valladolid, aunque su formación como licenciado estuvo a caballo entre ésta y la Universidad Autónoma de Madrid. Es DEA por el Instituto Universitario de Historia Simancas y Máster en Política y Democracia por la Universidad Nacional de Educación a Distancia. De igual modo, ha realizado varias estancias de investigación en centros de reconocido prestigio, como el Cañada Blanch Centre for Contemporary Spanish Studies de la London School of Economics and Political Science, el Instituto de Políticas y Bienes Públicos del Centro de Ciencias Humanas y Sociales del CSIC y en el History Department de Yale University. Es miembro del proyecto de investigación HAR2010-20762 "La Presidencia de Gobierno de Leopoldo Calvo Sotelo (1981-1982)" del Plan Nacional de I+D+i 2008-2011 del Ministerio de Ciencia e Innovación. Sus líneas de investigación giran en torno a la historia reciente de España y la construcción del Estado Autonómico Español. En 2010 fue distinguido con un accésit en el XI Premio Jóvenes Investigadores de la Asociación de Historia Contemporánea. Entre sus publicaciones destaca «El Día de la Región en Castilla y León: división y lucha partidista en torno a un símbolo autonómico (1983-1987)» en Ayer, 80, 2010, pp. 215-237.

URL: < http://studistorici.com/progett/autori/\#Elena >

\section{Per citare questo articolo:}

ELENA GONZÁLEZ, Esteban, «Reseña: Abdón, MATEOS, Historia de la UGT V. Contra la dictadura franquista, 1939-1975, Madrid, 2008, Siglo XXI, 273 pp.», Diacronie. Studi di Storia Contemporanea: Quando la classe operaia andava in paradiso, 13/2/2012,

URL:< http://www.studistorici.com/2012/02/13/elena_numero_9/ >

Diacronie Studi di Storia Contemporanea $\beta$ www.diacronie.it

Risorsa digitale indipendente a carattere storiografico. Uscita trimestrale. redazione.diacronie@hotmail.it

Comitato di redazione: Marco Abram - Giampaolo Amodei - Jacopo Bassi - Luca Bufarale - Alessandro Cattunar - Alice De Rensis Barbara Galimberti - Deborah Paci - Fausto Pietrancosta - Martina Sanna - Matteo Tomasoni - Luca Zuccolo

Diritti: gli articoli di Diacronie. Studi di Storia Contemporanea sono pubblicati sotto licenza Creative Commons 2.5.

Possono essere riprodotti a patto di non modificarne i contenuti e di non usarli per fini commerciali. La citazione di

estratti è comunque sempre autorizzata, nei limiti previsti dalla legge. 